\title{
The microwave emissivity variability of snow covered first-year sea ice from late winter to early summer: a model study
}

\author{
S. Willmes ${ }^{1}$, M. Nicolaus ${ }^{2}$, and C. Haas ${ }^{3}$ \\ ${ }^{1}$ University of Trier, Environmental Meteorology, 54286 Trier, Germany \\ ${ }^{2}$ Alfred-Wegener-Institut Helmholtz-Zentrum für Polar- und Meeresforschung, Bremerhaven, Germany \\ ${ }^{3}$ Earth \& Space Science \& Engineering, York University, Toronto, Canada
}

Correspondence to: S. Willmes (willmes@uni-trier.de)

Received: 14 October 2013 - Published in The Cryosphere Discuss.: 3 December 2013

Revised: 26 February 2014 - Accepted: 20 March 2014 - Published: 16 May 2014

\begin{abstract}
Satellite observations of microwave brightness temperatures between $19 \mathrm{GHz}$ and $85 \mathrm{GHz}$ are the main data sources for operational sea-ice monitoring and retrieval of ice concentrations. However, microwave brightness temperatures depend on the emissivity of snow and ice, which is subject to pronounced seasonal variations and shows significant hemispheric contrasts. These mainly arise from differences in the rate and strength of snow metamorphism and melt. We here use the thermodynamic snow model SNTHERM forced by European Re-Analysis (ERA) interim data and the Microwave Emission Model of Layered Snowpacks (MEMLS), to calculate the sea-ice surface emissivity and to identify the contribution of regional patterns in atmospheric conditions to its variability in the Arctic and Antarctic. The computed emissivities reveal a pronounced seasonal cycle with large regional variability. The emissivity variability increases from winter to early summer and is more pronounced in the Antarctic. In the pre-melt period (January-May, JulyNovember) the standard deviations in surface microwave emissivity due to diurnal, regional and inter-annual variability of atmospheric forcing reach up to $\Delta \varepsilon=0.034,0.043$, and 0.097 for $19 \mathrm{GHz}, 37 \mathrm{GHz}$ and $85 \mathrm{GHz}$ channels, respectively. Between 2000 and 2009, small but significant positive emissivity trends were observed in the Weddell Sea during November and December as well as in Fram Strait during February, potentially related to earlier melt onset in these regions. The obtained results contribute to a better understanding of the uncertainty and variability of sea-ice concentration and snow-depth retrievals in regions of high sea-ice concentrations.
\end{abstract}

\section{Introduction}

The temporal and spatial variability of sea-ice coverage and its physical properties have been operationally observed with satellite passive microwave radiometers for more than 30 years (e.g. Eisenman et al., 2014; Stroeve et al., 2012; Cavalieri and Parkinson, 2008; Parkinson and Cavalieri, 2008). Sea-ice concentration, the fractional coverage of sea ice per total area, is one of the most important parameters in an operational global monitoring of the polar oceans. It is derived daily in the Arctic and Southern oceans (e.g. Spreen et al., 2008; Markus and Cavalieri, 2000; Comiso et al., 1997; Cavalieri et al., 1996) from the microwave emissivity contrast of sea ice and the open ocean at microwave frequencies from $18 \mathrm{GHz}$ to $90 \mathrm{GHz}$ (e.g. Comiso, 1986; Eppler et al., 1992; Cavalieri et al., 1997; Lubin et al., 1997; Svendsen et al., 1987). These methods rely on emissivity proxies that are derived from the microwave brightness temperature $(\mathrm{Tb})$ data at different channels and polarizations. From a comparison with field data or other ground-truth references, tie points or transfer functions are deducted to allow for an inversion from microwave measurements to sea-ice concentration, or also surface properties like snow thickness or ice type (Markus and Cavalieri, 1998). Critical to this inversion are, however, seasonal and regional variations in the surface microwave emissivity that are caused by differences in atmospheric forcing and associated snow processes (Meier and Notz, 2010; Markus et al., 2006; Cavalieri et al., 1995; Gloersen and Cavalieri, 1986). As shown by Andersen et al. (2007) variations in sea-ice concentration retrievals over high-concentration Arctic sea ice are dominated 
by variations of snow emissivities. Their study concludes that long-term trends in surface and atmospheric properties may influence computed trends in sea-ice extent and area through their undetermined impact on microwave emissivities. Here we examine the impact of atmospheric conditions on snow properties and resulting emissivities to provide one constraint for a better understanding of the various contributors to seaice concentration retrieval uncertainties.

As far as hemispheric contrasts are concerned, the seasonal progression of snow melt differs significantly between the Arctic and the Antarctic (Andreas and Ackley, 1982; Nicolaus et al., 2006). In the Arctic, the stage of advanced melt (Livingstone et al., 1997) characterized by persistent melt water saturated snow is dominant during summer (Comiso and Kwok, 1996; Garrity, 1992). However, diurnal freeze-thaw cycles prevail on Antarctic sea ice (Willmes et al., 2006, 2009). The microwave emissivity of snow-covered sea ice is not only sensitive to the presence of melt water but varies in magnitude along with the seasonal changes that occur in snow stratification, grain sizes, density and the formation of ice layers even during the pre-melt period. For example, Cavalieri et al. (1990) and Comiso et al. (1997) have described how layered snow, and the associated presence of ice crusts and lenses, cause a low sea-ice concentration bias. Similarly, effects of snow layering during late summer on sea-ice concentration retrievals were evaluated by Markus and Dokken (2002).

In this paper we investigate some of the underlying causes of sea-ice concentration retrieval uncertainty, namely the temporal variability of the microwave emissivity of snow-covered first-year sea ice (FYI), in response to variable atmospheric conditions. Using a combined thermodynamic/microwave model forced by meteorological reanalysis data, we examine atmospherically driven snow metamorphism and its effect on the microwave emissivity of snow-covered sea ice in different regions of the Arctic and Antarctic. By using an identical, idealized initial snow cover throughout, we separate atmospheric effects from potential emissivity differences due to different regional snow and ice properties, or processes like snow accumulation, flooding and the effect of basal heat fluxes. Our snow cover is only modified by typical atmospheric forcing of each hemisphere. We want to identify the contribution of temporal and regional patterns in atmospheric energy fluxes to surface emissivity variations on Arctic and Antarctic sea ice and the resulting hemispheric contrasts in the seasonal Tb variability. We use the one-dimensional snow model SNTHERM (Jordan, 1991; Nicolaus et al., 2006) and the Microwave Emission Model for Layered Snowpacks (MEMLS, Wiesmann and Mätzler, 1999), adapted to snow on sea ice by Tonboe et al. (2006). Our approach represents an experimental study where quantify the impact of seasonal snow metamorphism in the absence of accumulation. With this setup we focus on emissivity variations in areas with high ice concentrations as described by Andersen et al. (2007) and we provide a data set of the seasonal variability and regional specifications of the microwave emissivity variability of FYI in the 19 to $85 \mathrm{GHz}$ frequency range. These data contribute to a better understanding of the uncertainty and variability of sea-ice concentration and snow-depth retrievals in regions of high sea-ice concentrations (Andersen et al., 2007; Markus et al., 2006; Comiso et al., 1997; Cavalieri, 1994).

\section{Data and methods}

\subsection{The snow model}

Physical snow properties of a layered snow pack on sea ice are simulated by the one-dimensional energy- and massbalance model SNTHERM. The model was created by Jordan (1991) and adapted and applied to sea ice by Jordan et al. (1999) and Andreas et al. (2004). Here we use the latest version by Nicolaus et al. (2006) and perform similar experiments, starting each simulation with a new initialization in winter (Arctic: January, Antarctic: July). We chose SNTHERM since it allows for high-resolution (mm-scale) simulations of the seasonal evolution of snow pack on sea ice as a function of atmospheric forcing and initial stratigraphy. Representing all snow layers by distinct control volumes in a moving vertical grid has the advantage of treating natural stratigraphic units within the snow. SNTHERM was forced with six-hourly data of the $2 \mathrm{~m}$ air temperature, relative humidity, $10 \mathrm{~m}$ wind speed, incoming shortwave radiation and downward longwave radiation obtained from the European Center for Medium Range Weather Forecast (ECMWF) ERA interim reanalysis data at $0.75^{\circ}$ resolution (Dee et al., 2011).

\subsection{The microwave model}

The Microwave Emission Model for Layered Snowpacks (MEMLS, Wiesmann and Mätzler, 1999; Mätzler and Wiesmann, 1999) is used to compute microwave brightness temperatures from vertical snow profiles. We use a sea-ice version of MEMLS (Tonboe et al., 2006; Tonboe, 2010) to account for the effect of sea-ice dielectric properties on microwave brightness temperatures. The model calculates $\mathrm{Tb}$ at frequencies between $5 \mathrm{GHz}$ and $200 \mathrm{GHz}$ for vertical and horizontal polarizations. Here we use $\mathrm{Tb}$ values at frequencies of $19 \mathrm{GHz}, 37 \mathrm{GHz}$ and $85 \mathrm{GHz}$ (hereafter referred to as $19 \mathrm{~V}, 19 \mathrm{H}, 37 \mathrm{~V}, 37 \mathrm{H}, 85 \mathrm{H}$ and $85 \mathrm{~V}$ ), to compare results with the sensors used in operational satellite microwave monitoring, i.e. the Special Sensor Microwave Imager (SSM/I) radiometer and (with similar frequencies) the Advanced Microwave Scanning Radiometer (AMSR). All simulations are at $50^{\circ}$ incidence angle, as typical for conically scanning radiometers. Although we had to choose specific frequencies and incidence angles for this study, results are also representative for adjacent frequencies and incidence angles. 

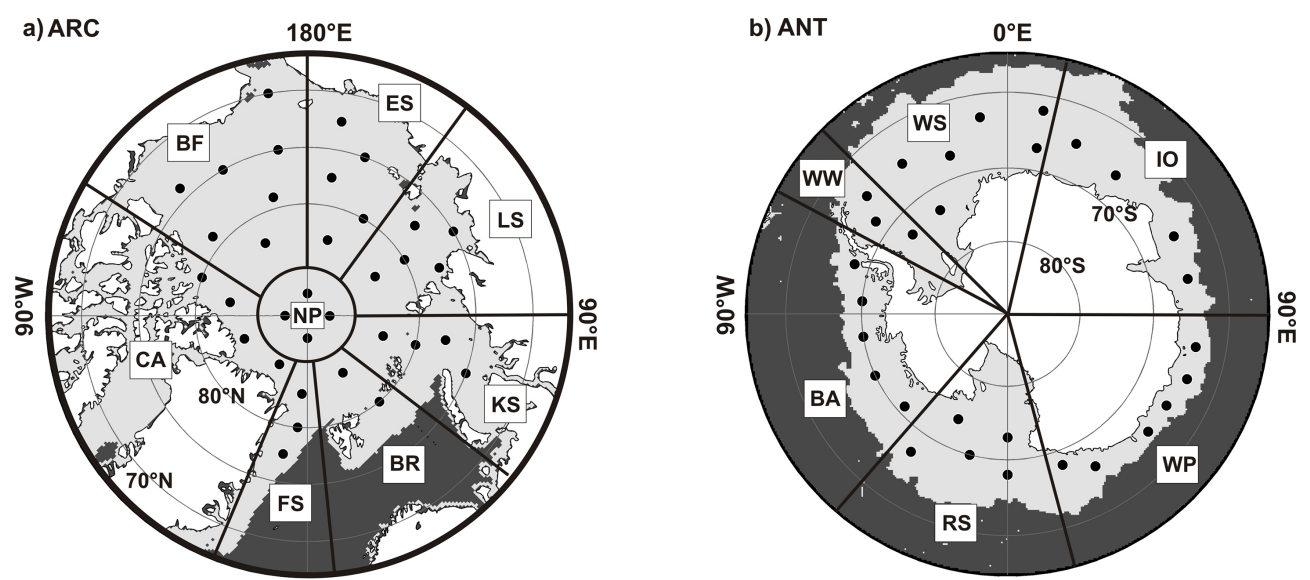

Fig. 1. Maps of the Arctic (a) and Antarctic (b) showing the regions referred to and the locations where atmospheric forcing data were extracted. The grey area indicates the average sea-ice extent for 1 June (Arctic) and 1 December (Antarctic), 2000-2009. Regions indicated are: Arctic: NP (North Pole), FS (Fram Strait), BR (Barents Sea), KS (Kara Sea), LS (Laptev Sea), ES (East Siberian Sea), BF (Beaufort Sea), CA (Canadian Arctic), Antarctic: WW (western Weddell Sea), WS (Weddell Sea), IO (Indian Ocean), WP (western Pacific), RS (Ross Sea), BA (Bellingshausen-Amundsen Seas).

\subsection{Combined model study}

SNTHERM and MEMLS are used in a combined model study to infer the temporal evolution of sea-ice microwave brightness temperatures for typical atmospheric forcing conditions in the Arctic and Antarctic. Since the main drivers for snow metamorphism are temperature and moisture gradients within the snow, both of which are predominantly influenced by atmospheric conditions, we neglect basal (ocean) heat flux and sea-ice growth. Moreover, when the snow becomes wet in the lower snow layers, the snow-ice interface approaches the melting point, independent of heat flux through the ice (Nicolaus et al., 2009).

We perform our experiments with $60 \mathrm{~cm}$ of sea ice with a density of $910 \mathrm{~kg} \mathrm{~m}^{-3}$ that is covered with an initial snow profile of $30 \mathrm{~cm}$ thickness. The snow layer at initialization is represented by 30 layers of $1 \mathrm{~cm}$ thickness with a density of $320 \mathrm{~kg} \mathrm{~m}^{-3}$ and a snow grain size of $1 \mathrm{~mm}$. Below the snow we add 12 layers of sea ice with $5 \mathrm{~cm}$ thickness and a salinity of $7 \mathrm{ppt}$. These initial conditions are idealized and not representative of regional differences in snow depth and snow stratigraphies (e.g. Warren et al., 1999; Powell et al., 2006; Massom et al., 2001; Nicolaus et al., 2009). However, identical initial conditions are required to facilitate the isolated analysis of atmospheric effects on emissivities alone and to determine regional differences. In defining the presented snow initialization we consider the mentioned studies addressing first-year sea-ice snow properties in both hemispheres and use this as an experimental setup that combines characteristics of both hemispheres. This approach enables us to identify the net effect of atmospheric forcing on regional changes in the microwave emissivity, without strong impacts of the initial (winter) snow properties.
The temperature in the lowest ice layer is assumed to be at the freezing point of $-1.8^{\circ} \mathrm{C}$ while the initial snow surface temperature is set to the ERA interim air temperature for each location and year. Linear temperature profiles are assumed in sea ice and snow at initialization with the temperature at the snow/ice interface representing one third of the total temperature gradient from the sea-ice bottom to the snow surface.

We forced SNTHERM with six-hourly ERA interim reanalysis data for 10 years (2000 to 2009), at 34 locations for 8 different regions in the Arctic (January to June) and at 29 locations for 6 regions in the Antarctic (July to December, Fig, 1) where sea ice is regularly present at the start of simulations and on average persists at least until May (Arctic) or November (Antarctic).

The interface between the snow and the emission model is provided by the vertical profiles of snow temperature, density, grain size and wetness. The optical grain diameter $d_{\mathrm{o}}$ provided by SNTHERM was recalculated into the exponential correlation length $p_{\mathrm{ex}}$ for usage in MEMLS according to Eq. (1), where $\rho_{\mathrm{s}}$ and $\rho_{i}$ are snow and ice densities in $\mathrm{kg} \mathrm{m}^{-3}$, respectively (Mätzler, 2002).

$p_{\mathrm{ex}}=F \cdot d_{\mathrm{o}} \cdot\left(1-\rho_{\mathrm{s}} \cdot \rho_{i}^{-1}\right)$

The scaling coefficient $F$ in Eq. (1) is adjusted to ensure the best alignment of our simulated $\mathrm{Tb}$ data with the Nasa Team FYI tie points (Cavalieri et al., 1994) after 5 days of SNTHERM spin-up time. In doing so, a value of 0.12 was obtained for $F$. The use of a correlation length correction scheme for microwave modelling has also been demonstrated by previous studies. Wiesmann et al. (2000) obtained best results for the combination of SNTHERM and MEMLS when $p_{\text {ex }}$ was calculated by scaling $d_{\mathrm{o}}$ with a value of 0.16 . Durand et al. (2008) applied a linear relationship between $p_{\text {ex }}$ 
and the natural logarithm of the maximum grain diameter, while Langlois et al. (2012) and Montpetit et al. (2013) used an approach similar to Eq. (1), including an additional factor of 2/3 according to Mätzler (2002), and obtained scaling coefficients of 0.1 and 1.3 , respectively. In general, the calculation of correlation lengths and choice of correction factors depends on the applied model combinations.

\subsection{Satellite $\mathbf{T b}$ data}

In many algorithms, microwave brightness temperatures are used in the form of either a polarization ratio (PR, Eq. 2) or a gradient ratio (GR, Eq. 3) using different microwave polarizations and frequencies (Cavalieri et al., 1984).

$$
\begin{aligned}
& \mathrm{PR}=(19 \mathrm{~V}-19 \mathrm{H}) \cdot(19 \mathrm{~V}+19 \mathrm{H})^{-1} \\
& \mathrm{GR}=(37 \mathrm{~V}-19 \mathrm{~V}) \cdot(37 \mathrm{~V}+19 \mathrm{~V})^{-1}
\end{aligned}
$$

These two parameters eliminate the effect of physical snow temperatures on observed brightness temperatures, such that changes of PR and GR are only due to emissivity changes in the footprint of the radiometer. Here, we use PR and GR, together with the microwave emissivities at different polarizations and frequencies to investigate their seasonal changes in context with prevailing atmospheric forcing in different regions.

For a comparison with satellite data we use the Defense Meteorological Satellite Program (DMSP) Special Sensor Microwave Imager (SSM/I)-Special Sensor Microwave Imager Sounder (SSMIS) Daily Polar Gridded Brightness Temperatures data set (Maslanik and Stroeve, 2004) provided by the US National Snow and Ice Data Center (NSIDC). Sea Ice Concentrations from Nimbus-7 SMMR and DMSP SSM/ISSMIS Passive Microwave Data product (Cavalieri et al., 1996) were used to create a subset of satellite microwave brightness temperatures at high sea-ice concentrations only because our results represent emissivity changes in regions of $100 \%$ ice concentration.

\section{Results}

\subsection{Comparison of simulated and observed brightness temperatures}

With our simulations we do not aim to achieve a high pointto-point agreement between observations and simulations because we cannot properly include the effects of surface processes like snow accumulation and redistribution, flooding, or snow ice formation. Moreover, the applied simplifications (equal snow pack at initialization) and the additional impact of open water and sea-ice drift on observed $\mathrm{Tb}$ complicate a point-to-point comparison of our results with satellite data.

Figure $2 \mathrm{a}$ and $\mathrm{b}$ show the PR and GR ratios obtained from simulated brightness temperatures for the Arctic and Antarctic, respectively. In addition, the figures show PR and
GR ratios from observed brightness temperatures extracted from the daily polar gridded satellite data sets for all regions where the sea-ice concentration exceeds $90 \%$. As expected, the simulated data are closely aligned with the $100 \%$ sea-ice concentration lines (white dotted lines, Cavalieri et al., 1984, 1994). PR and GR ratios show a larger range of variability and scatter in the Antarctic than in the Arctic, both in observations and simulations. In general, the simulated data cover a narrower range of $\mathrm{PR} / \mathrm{GR}$ ratios than observed data. This is mostly due to the fact that the model results (point-scale) represent $100 \%$ sea-ice concentration, whereas observed data have been extracted for sea-ice concentration $>90 \%$, and therefore are affected by emissivity variations arising from different open water fractions, surface heterogeneity and seaice drift. Since the simulated data represent a sea-ice concentration of $100 \%$ the presented PR/GR variability arises exclusively from changes in the snowpack. The last month of simulations (Arctic: June, Antarctic: December) is highlighted by red dots to indicate the effect of beginning melt processes. In June in the Arctic, there is a pronounced cluster of melt signals with GR values close to zero. In the Antarctic there is less change in PR and GR ratios at the beginning of summer, i.e. in December. The frequency distributions of simulated and observed PR and GR values at the bottom of Fig. $2 \mathrm{a}$ and $\mathrm{b}$ indicate a small bias between observed and simulated data, and narrower distributions with less variability of the simulated data. Although the simulated values are within a realistic range of observed $\mathrm{PR}$ and $\mathrm{GR}$, the simulations indicate on average higher PR (Arctic: +0.005; Antarctic: +0.002) and lower GR (Arctic: -0.005; Antarctic: -0.014). Possible reasons for these differences were mentioned above. Also notable is a large contribution of simulated GR values close to zero, especially in the Arctic, which is not found in the observed data. These GR values are caused by melting snow and result only from data in the last month of simulations (Arctic: June). We suggest that due to different open water fractions, surface heterogeneity and a lower temporal resolution this signal contribution is smoothed in the observed data. As demonstrated by the graphs, the hemispheric differences that are found in the satellite data (i.e. the frequency distribution of PR is flatter and low GR values are less frequent in the Antarctic than in the Arctic), are also present in the simulated data.

Figure 2c and d show associated brightness temperatures and their frequency distributions. Modal values of observations and simulations are similar, and the distributions of simulated brightness temperatures are narrower as for the PR and GR ratios. However, simulated 19V and 37V brightness temperatures show an additional peak at high temperatures of $273 \mathrm{~K}$. In both hemispheres, Tb values of $273 \mathrm{~K}$ are reached in the simulations when the snow starts to melt. This behaviour is not clearly seen in the observed $\mathrm{Tb}$ which is probably due to the melt signal being smoothed as previously stated for differing GR values. 
a) ARC PR vs. GR
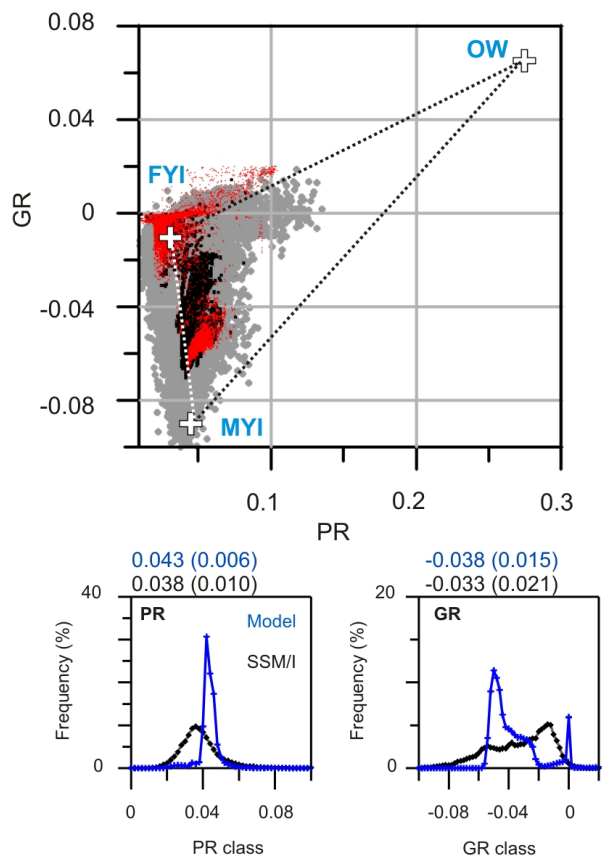

c) ARC $37 \mathrm{~V}$ vs. $19 \mathrm{~V}$
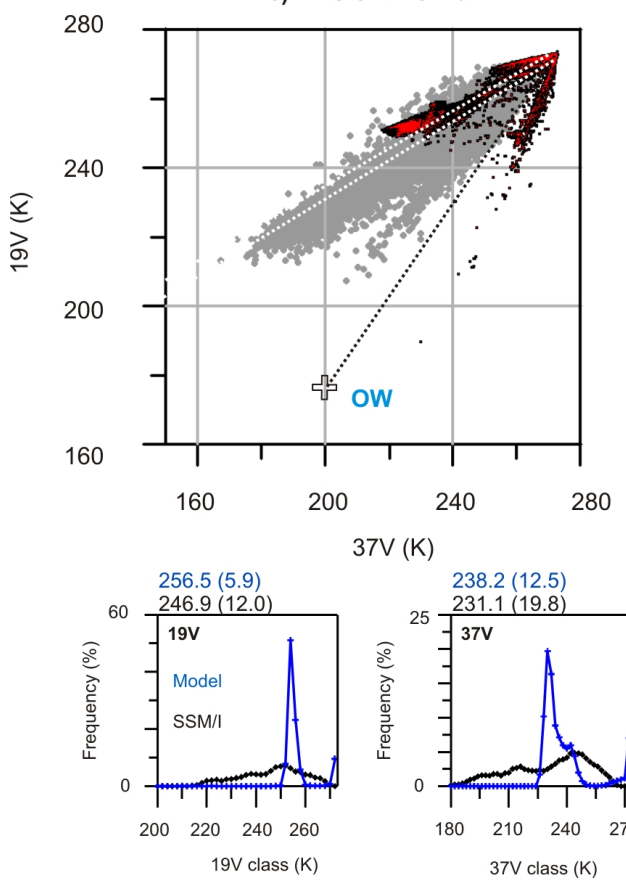
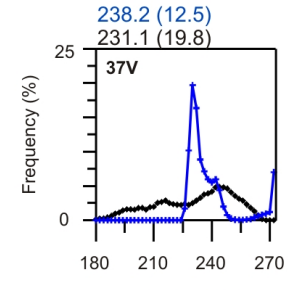
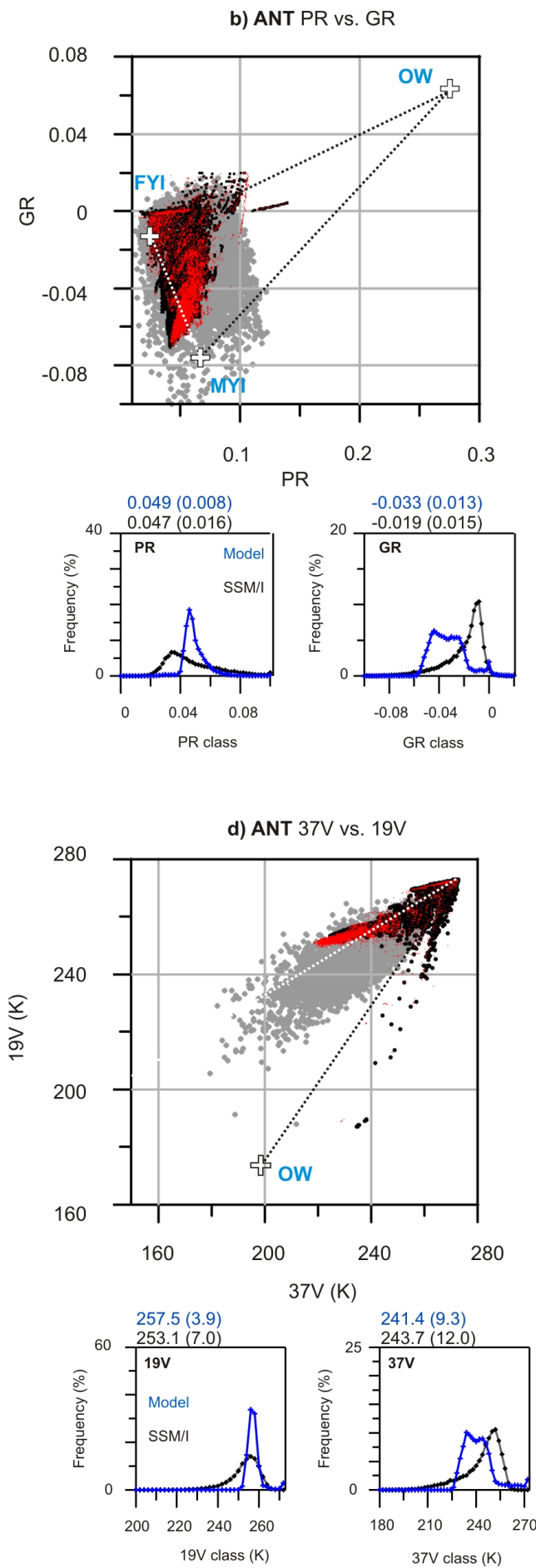

Fig. 2. Simulated polarization and gradient ratios (PR, GR, black) for the Arctic (a, January to June) and Antarctic (b, July to December) and brightness temperatures at 37V and 19V for the Arctic (c) and Antarctic (d), 4 times daily data, 2000-2009. Red dots indicate last month of simulations. Daily values of observed satellite $\mathrm{Tb}$ for area with sea-ice concentrations above $90 \%$ are shown by grey dots for comparison. Tie points for open water (OW) and (in a, b only) first-year ice (FYI) as well as multi-year ice (MYI) are indicated by crosses. $100 \%$ sea-ice concentration lines are shown by white dotted lines, while different lines in (c) show lines for summer and winter, respectively. (a)-(d) with frequency distributions of modelled (blue) and observed data (black, values extracted where sea-ice concentrations exceeds $90 \%$ ). The means and standard deviations are indicated by numbers. 


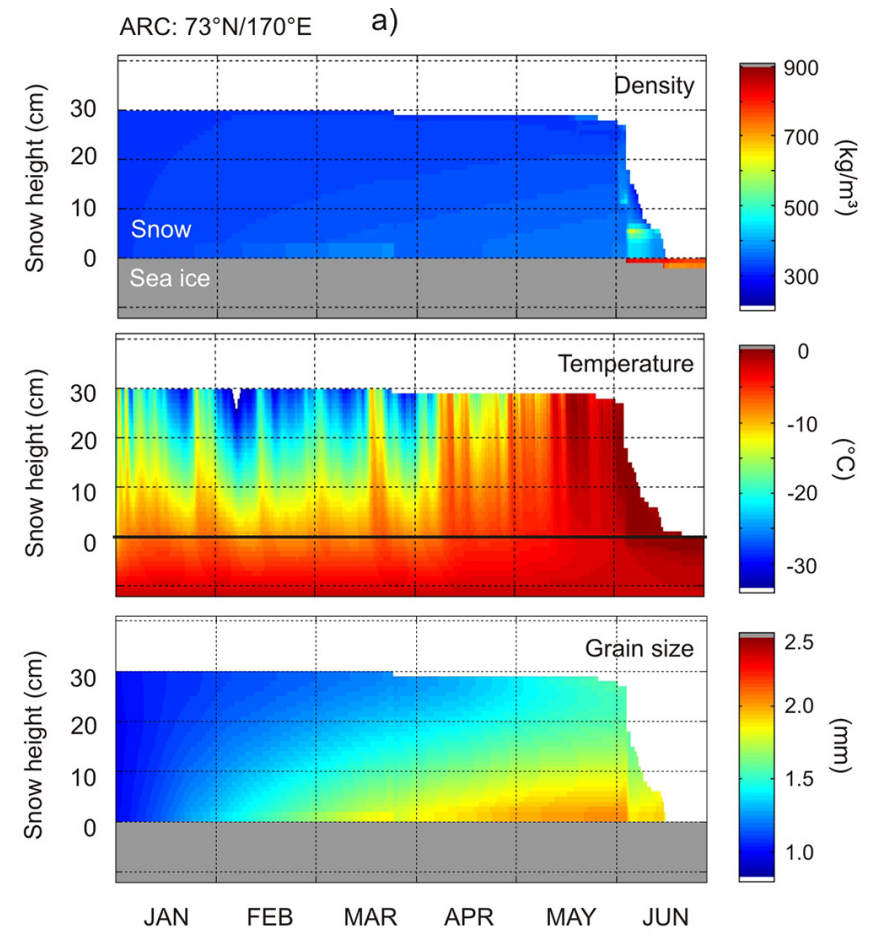

c)

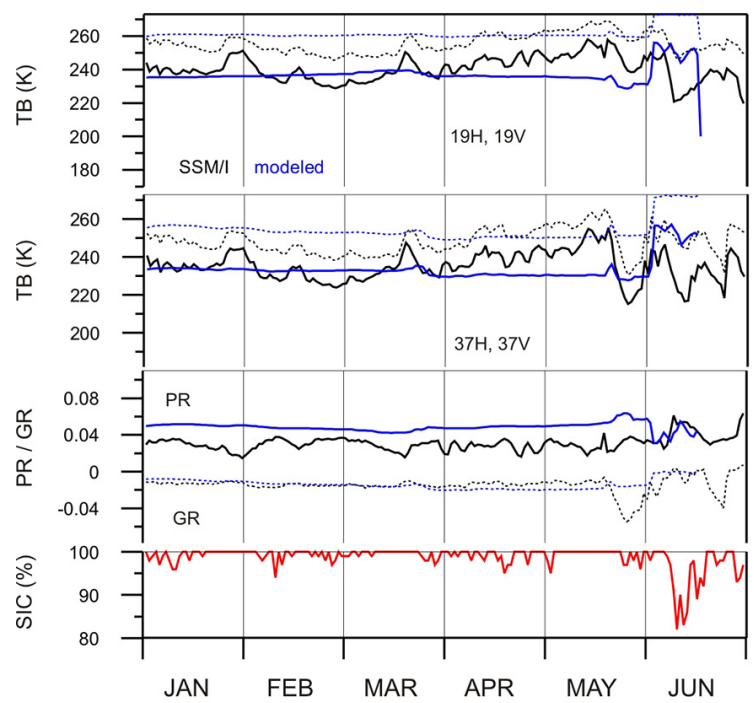

ANT: $67^{\circ} \mathrm{S} / 145^{\circ} \mathrm{W}$
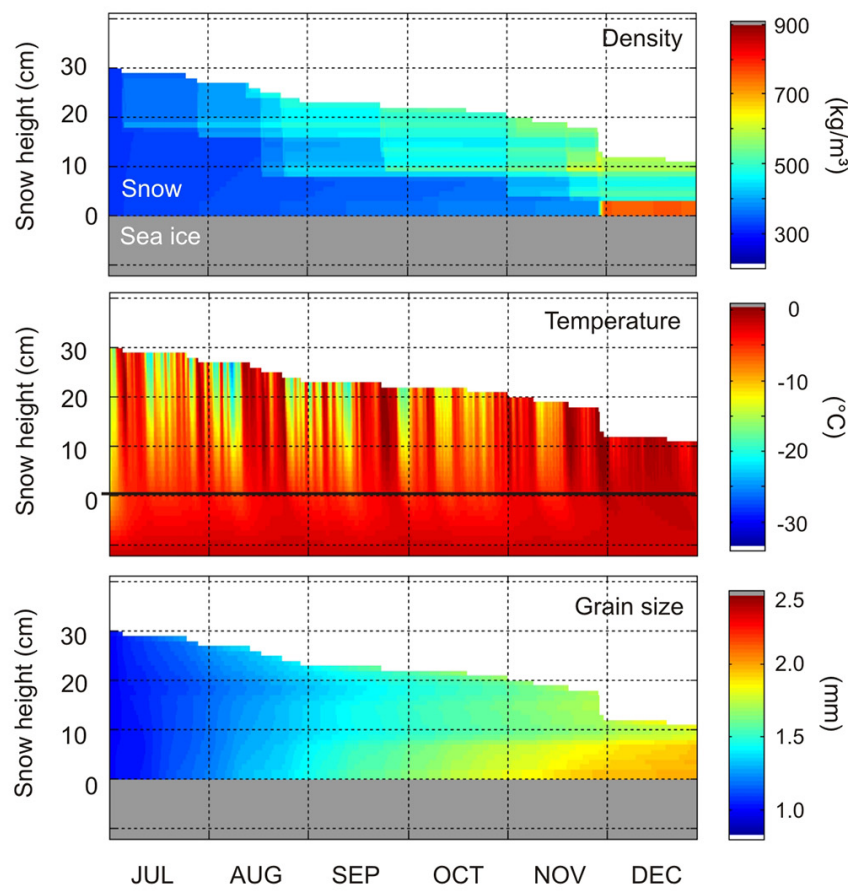

d)

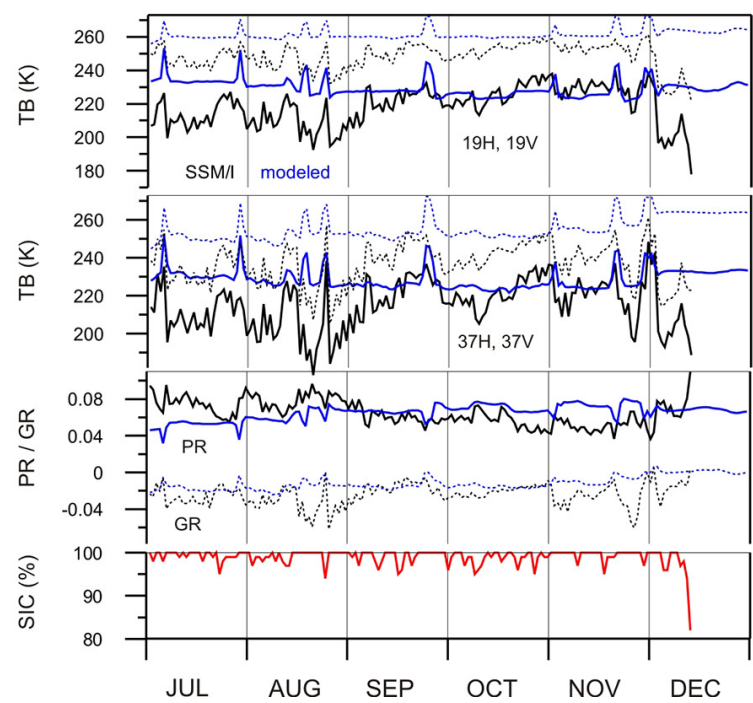

Fig. 3. Snow pack evolution from SNTHTERM: Density, Temperature and Grain size for the Arctic (a, January-June $2008,70^{\circ} \mathrm{N} / 170^{\circ} \mathrm{W}$ ) and Antarctic (b, July-December 2008, $70^{\circ} \mathrm{S} / 85^{\circ} \mathrm{W}$ ). Associated simulated (blue) and observed (black) $19 \mathrm{GHz}$ and $37 \mathrm{GHz}$ brightness temperatures (bold: horizontal pol.; dotted: vertical pol.), Polarization Ratio (PR) and Gradient Ratio (GR) as well as Nasa Team sea-ice concentrations (red) for the same positions in the Arctic (c) and Antarctic (d).

The SNTHERM snow pack evolution for two locations in the Arctic and Antarctic is presented in Fig. 3a and b, respectively. The two profiles are characteristic of the general hemispheric differences in snow pack evolution described by Nicolaus et al. (2006). In the Arctic, melting does not occur before June and is followed by a rapid thinning and disappearance of the snow while density changes in the pre- melt period are only small and grain sizes increase predominantly from the bottom. In contrast, in the Antarctic, the first melt event occurs already in July and is followed by multiple freeze-thaw cycles, which cause a layering of the snow, together with increasing densities and increasing grain sizes also in the upper layers. 
a) ARC $19 \mathrm{~V}, 37 \mathrm{~V}, 85 \mathrm{~V}$

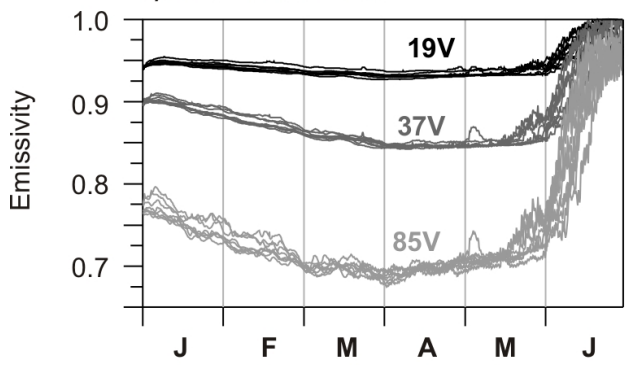

c) ARC $19 \mathrm{H}, 37 \mathrm{H}, 85 \mathrm{H}$

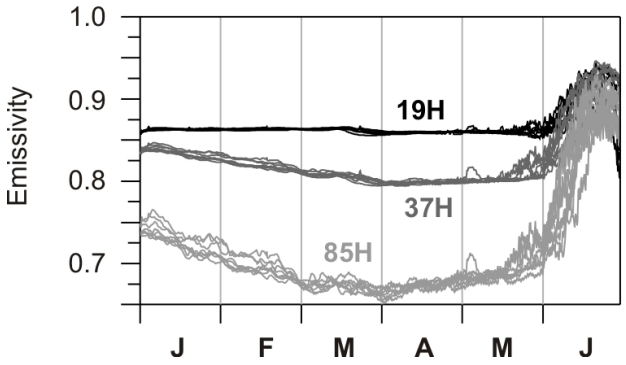

b) ANT $19 \mathrm{~V}, 37 \mathrm{~V}, 85 \mathrm{~V}$

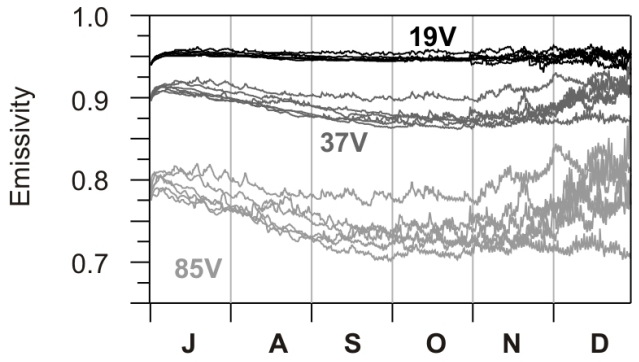

d) ANT $19 \mathrm{H}, 37 \mathrm{H}, 85 \mathrm{H}$

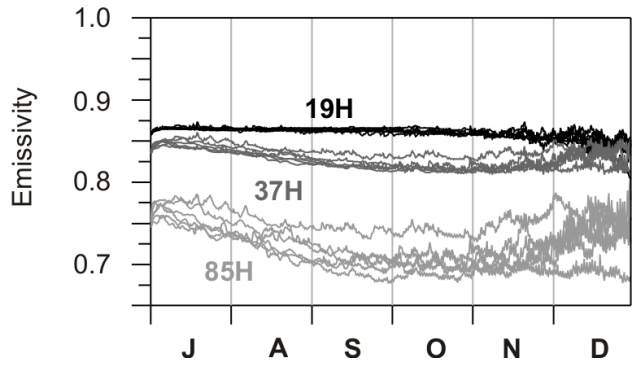

Fig. 4. The seasonal evolution of simulated $19 \mathrm{GHz}, 37 \mathrm{GHz}$ and $85 \mathrm{GHz}$ emissivities at vertical (a, b) and horizontal (c, d) polarizations for Arctic regions (a, c, January to June) and Antarctic regions (b, d, July to December). Data are averaged for the period from 2000-2009.

Table 1. Mean and standard deviation of emissivities at 19, 37 and $85 \mathrm{GHz}$ (vertical polarization) for different SNTHERM initialization and MEMLS parameterization for region WW during October, derived from 4-times daily values, 2000-2009. REF: initialization profile used within this study, zs 15: $15 \mathrm{~cm}$ snow depth, zs50: $50 \mathrm{~cm}$ snow depth, dg15: $1.5 \mathrm{~mm}$ grain size, S02: sea-ice salinity $2 \mathrm{ppt}$, S12: sea-ice salinity $12 \mathrm{ppt}$, D270: snow density $270 \mathrm{~kg} \mathrm{~m}^{-3}$, D370: snow density $370 \mathrm{~kg} \mathrm{~m}^{-3}$, lay1: an ice layer with $910 \mathrm{~kg} \mathrm{~m}^{-3}$ density is included in the middle of the profile right from the start.

\begin{tabular}{llrrrrrrrrr}
\hline & & REF & zs15 & zs50 & $\operatorname{dg} 15$ & S02 & S12 & D270 & D370 & lay1 \\
\hline $\mathrm{e} 19 \mathrm{v}$ & mean & 0.946 & 0.951 & 0.941 & 0.928 & 0.952 & 0.935 & 0.934 & 0.956 & 0.931 \\
& std & 0.01 & 0.01 & 0.01 & 0.02 & 0.01 & 0.01 & 0.01 & 0.01 & 0.01 \\
$\mathrm{e} 37 \mathrm{~V}$ & mean & 0.873 & 0.895 & 0.864 & 0.814 & 0.874 & 0.870 & 0.832 & 0.908 & 0.867 \\
& std & 0.04 & 0.03 & 0.04 & 0.05 & 0.04 & 0.03 & 0.05 & 0.02 & 0.04 \\
$\mathrm{e} 85 \mathrm{v}$ & mean & 0.738 & 0.728 & 0.745 & 0.660 & 0.737 & 0.737 & 0.659 & 0.808 & 0.743 \\
& std & 0.07 & 0.08 & 0.07 & 0.09 & 0.07 & 0.07 & 0.09 & 0.06 & 0.08 \\
$\mathrm{PR}$ & mean & 0.048 & 0.049 & 0.046 & 0.046 & 0.042 & 0.054 & 0.045 & 0.050 & 0.076 \\
& std & 0.01 & 0.01 & 0.01 & 0.01 & 0.01 & 0.01 & 0.01 & 0.01 & 0.01 \\
$\mathrm{GR}$ & mean & -0.040 & -0.030 & -0.043 & -0.065 & -0.042 & -0.036 & -0.058 & -0.025 & -0.035 \\
& std & 0.02 & 0.01 & 0.01 & 0.02 & 0.01 & 0.02 & 0.02 & 0.01 & 0.02 \\
\hline
\end{tabular}

Time series of associated simulated and observed $19 \mathrm{H}$, $19 \mathrm{H}, 37 \mathrm{H}$ and $37 \mathrm{~V}$ brightness temperatures are shown in Fig. 3c, $d$ together with the coincidentally retrieved sea-ice concentration at the respective grid points. The simulated data are very smooth in comparison to satellite $\mathrm{Tb}$, while occasionally simulated larger peaks and excursions are also found in the observed $\mathrm{Tb}$, though superimposed to a substantially larger background variability. Especially when the snow is dry, the observed $\mathrm{Tb}$ variability is likely a consequence of other temporal changes of ice and snow properties at the respective grid points, e.g. due to variations in roughness, age and salinity of thin ice (e.g. Eppler et al., 1992). The largest differences between simulations and observations are found for Arctic PR values which are mainly due to the fact that the simulations overestimate $19 \mathrm{~V}$ by approximately $5 \mathrm{~K}$ on average which could be an effect of the snow depth of $30 \mathrm{~cm}$ being overestimated in this location.

\subsection{The simulated microwave emissivity variability}

Simulated microwave emissivities at 19,37 and $85 \mathrm{GHz}$ show pronounced seasonal changes within the considered period (Fig. 4). The average magnitude of seasonal changes for all presented frequencies and both polarizations is stronger in the Arctic than in the Antarctic, with a substantial increase 
occurring in the month of June in the former (Fig. 4a, c). This emissivity increase is attributed to the onset of the advanced melt stage (Livingstone et al., 1997; Drobot and Anderson, 2001; Markus et al., 2009; Belchansky et al., 2004), when the presence of melt water within the snow becomes persistent throughout the day. While all channels approach values up to 1 during June in the Arctic, minimum average seasonal emissivity values are as low as $0.68(0.65)$ for $85 \mathrm{~V}(85 \mathrm{H})$, $0.85(0.79)$ for $37 \mathrm{~V}(37 \mathrm{H})$ and $0.94(0.86)$ for $19 \mathrm{H}(19 \mathrm{~V})$. In the Antarctic (Fig. 4b, d) the seasonal emissivity minima are on average 0.03 and 0.01 higher than in the Arctic for 85 and $37 \mathrm{GHz}$ channels, respectively. The inter-annual average of maxima does not reach a value of 1 and is $0.97(0.87)$ for $19 \mathrm{~V}(19 \mathrm{H}), 0.94(0.87)$ for $37 \mathrm{~V}(37 \mathrm{H})$ and $0.85(0.79)$ for $85 \mathrm{~V}(85 \mathrm{H})$.

In the Antarctic the regional differences in emissivities are more distinct than in the Arctic. The advanced melt stage is found with much lower probability than in the Arctic (Willmes et al., 2006, 2009). The observed tendency towards higher emissivities in the Antarctic at the beginning of summer is rather an effect of averaging single profiles where temporally-limited thaw events causing very high emissivities for the duration of melt are occurring at different points in time. The different melt process in the two hemispheres are described by a study of Nicolaus et al. (2006). They show that the impact of melting and sublimation/evaporation on the snow cover decrease is very different between the Arctic and Antarctic, e.g. the ratio of evaporated snow mass to melted snow mass per unit area amounts to approximately 4.2 in the Antarctic and only 0.75 in the Arctic, which also certainly impacts the evolution of microwave emissivities.

\subsection{Initialization effects}

Results of our simulations strongly depend on the assumed initial snow properties. We performed test runs with both models by varying the assumed sea-ice salinity of $7 \mathrm{ppt}$ (in MEMLS) by $\pm 5 \mathrm{ppt}$ (S02, S12) as well as the initial snow profile (for SNTHERM) in grain size $(+0.5 \mathrm{~mm}$, dg15), thickness $(15 \mathrm{~cm}$ and $50 \mathrm{~cm}, \mathrm{zs} 15, \mathrm{zs} 50)$ and density $\left( \pm 50 \mathrm{~kg} \mathrm{~m}^{-3}, \mathrm{D} 270, \mathrm{D} 370\right)$; wetness is always set to zero at the start of simulations. Additionally, one test run was performed, where a thin ice layer was included at a snow depth of $10 \mathrm{~cm}$ (lay1). This approach revealed that the mean emissivity is biased by initialization, while its diurnal, regional and temporal variability (all three expressed in combination by monthly standard deviations) as well as hemispheric differences change in the same ways regardless of the mean signal (Table 1). The $37 \mathrm{GHz}$ and $85 \mathrm{GHz}$ frequencies are much more sensitive to initialization during the pre-melt period than $19 \mathrm{GHz}$ which is an effect of their smaller penetration depth in comparison to $19 \mathrm{GHz}$ and the resulting larger impact of changes in the snow cover. If an initial snow density of $270 \mathrm{~kg} \mathrm{~m}^{-3}$ is assumed in the snow pack, the mean $19 \mathrm{~V}$ emissivity in the WW region in October decreases from
0.946 to 0.934 , while a change from 0.873 to 0.832 and from 0.738 to 0.659 is noted for $37 \mathrm{~V}$ and $85 \mathrm{~V}$, respectively. The associated changes in the monthly standard deviation depend on the introduced changes in initialization. For D270 they amount to $+0.01(19 \mathrm{~V}),+0.01(37 \mathrm{~V})$ and $+0.02(85 \mathrm{~V})$ and for D370 the standard deviation decreases by $-0.02(37 \mathrm{~V})$ and $-0.01(85 \mathrm{~V})$. In general, Table 1 indicates that in thinner snow an increased microwave emissivity variability. The same holds when snow grains are larger at the beginning of initialization $(\mathrm{dg} 15)$. The impact of the initial sea-ice salinity (S02, S12) and the presence of ice layers (lay1) on the simulated emissivity variability is very small. As such, Table 1 provides insight into the sensitivity of our results to ambiguities in the chosen snowpack initialization.

\subsection{Regional and hemispheric differences}

Figure 5 shows the mean and standard deviations of emissivities computed during standard runs (compare Table 1) for different regions, polarizations, and frequencies, for the 4th month of simulations (Arctic: April, Antarctic: October). It can be seen that the regions show differences of up to 0.01 , 0.04 and 0.07 in their emissivity variations (std. deviation) for $19 \mathrm{~V}, 37 \mathrm{~V}$ and $85 \mathrm{~V}$, respectively. In general, the Antarctic regions show a larger range of emissivity values with a tendency towards higher mean emissivities than in the Arctic. The hemispheric contrast is even more pronounced in the PR and GR variabilities (Fig. 5e, f). While both, PR and GR variabilities are small in the Arctic, the Southern Ocean (except Indian Ocean, IO) shows significantly larger mean values and regional standard deviations in both parameters.

This finding also holds for the other months of the presummer period (Table 2). Within hemispheres, the regional variability is weaker in the Arctic than in the Southern Ocean. The NP, FS, BR and KS regions reveal a stronger range of emissivities than the other Arctic regions. As these regions are closer to the open water and marine climate of the North Atlantic, the larger variability in these regions could be due to the potential earlier occurrence of short freezethaw events. In the Antarctic, the largest emissivity ranges are found in the Weddell Sea (WW, WS), Ross Sea (RS) and Bellingshausen-Amundsen Seas (BA). When melt processes start (June, December), the emissivity range per region is largest, since the high emissivities where and when melt has already started contrasts with when and where it has not. An exception is found in the IO and WS regions where the emissivity variability stays close to the pre-melt period even in December (Table 2). We provide standard deviations of the mean microwave emissivity per month, region, frequency and polarization in Table 2 . These values can be used as a reference to assess the sensitivity of tie points for satellite retrievals of sea-ice concentration and snow thickness to emissivity variations.

The average seasonal evolution of the microwave emissivity variability as well as of PR and GR in both hemispheres 
a)

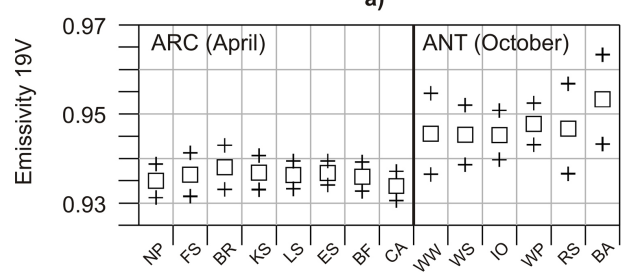

c)

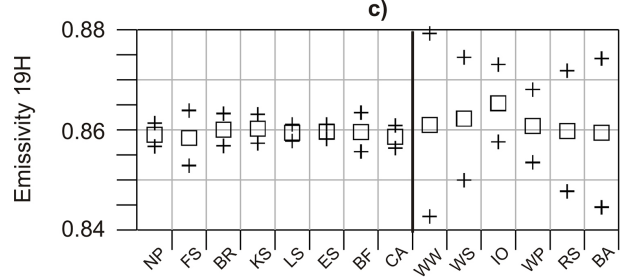

e)

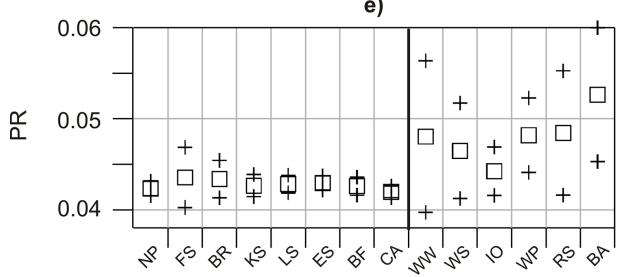

b)

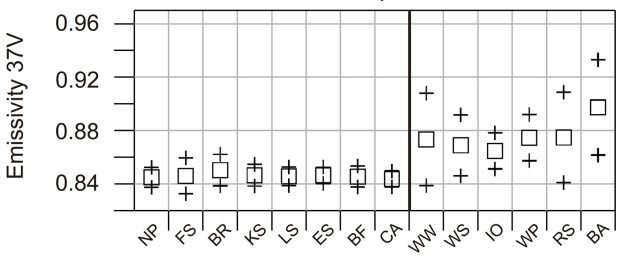

d)

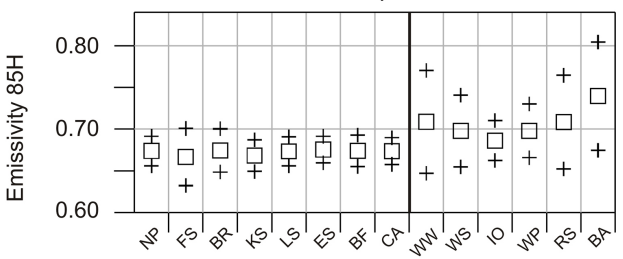

엉

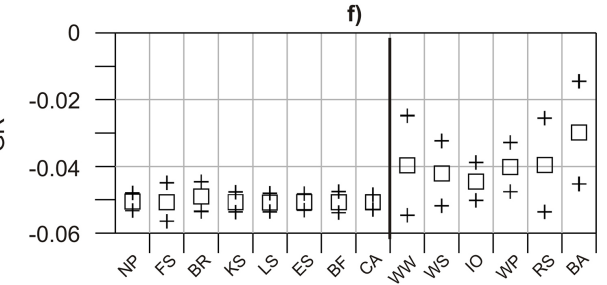

Fig. 5. Mean (squares) and standard deviation (crosses) of simulated emissivity values indicating the daily, spatial and inter-annual variability in the 4th month of simulation (ARC: April, ANT: October) for emissivities at (a) $19 \mathrm{~V}$, (b) $37 \mathrm{~V}$, (c) $19 \mathrm{H}$, (d) $85 \mathrm{H}$ as well as (e) polarization ratio and (f) gradient ratio.
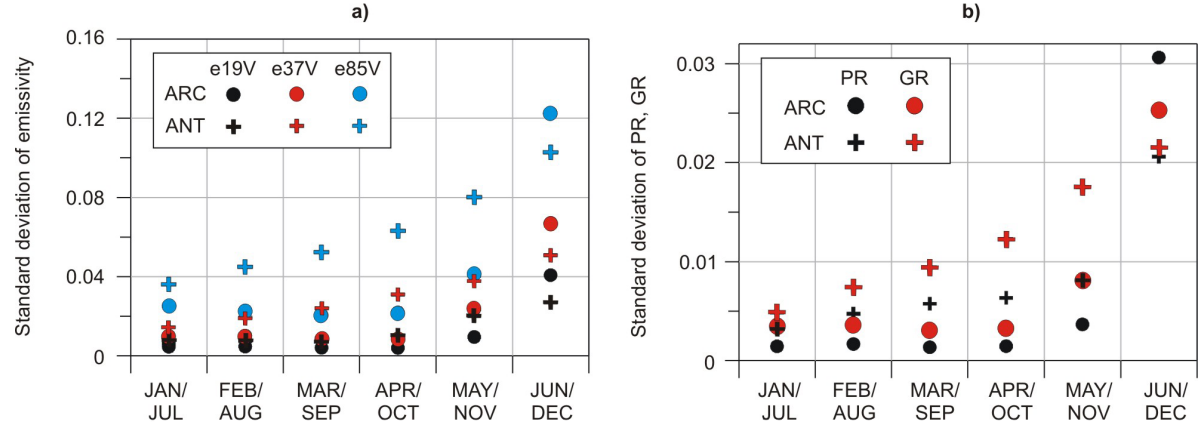

Fig. 6. Seasonal evolution of simulated, monthly standard deviations of (a) emissivities at 19 (black), 37 (red) and $85 \mathrm{GHz}$ (blue), each at vertical polarization, for the Arctic (circles) and Antarctic (crosses) and (b) PR (black) and GR (red) for the Arctic (circles) and Antarctic (crosses). Monthly values, characterizing the diurnal, regional and inter-annual variabilities, January to June (Arctic) and July to December, Antarctic, 2000-2009.

is shown in Fig. 6. The diurnal and regional emissivity variability increases from late winter to early summer for all frequencies in both hemispheres while it is, in general, larger in the Antarctic throughout the season (Fig. 6a, crosses). The Arctic experiences the largest increase in emissivity variability from the months of May to June, when persistent melt commences in some regions. The hemispheric contrast increases with frequency. Similar observations hold for the monthly values of PR and GR (Fig. 6b). The GR variability during the pre-melt period is especially more pronounced in the Antarctic. In comparison to Fig. 5 the presented values illustrate that the regional emissivity variability can de- viate substantially from the average hemispheric variability. For example, the standard deviation of $37 \mathrm{~V}$ during October is 0.038 in the BA region and 0.018 in the WP region (compare Figure 5b), while it is 0.029 when the entire Antarctic is considered. This finding is critical for the formulation of tie points that are valid for an entire hemisphere and suggests that regional differences should be taken into account.

\subsection{Hemispheric characteristics}

Here we examine which snow processes could be most relevant for the simulated differences in emissivity variations 
Table 2. Monthly standard deviation of emissivity (here: 0-100\%) per region, month, frequency and polarization.

\begin{tabular}{|c|c|c|c|c|c|c|c|c|c|c|c|c|c|c|c|c|}
\hline & & \multicolumn{8}{|c|}{ ARC } & & \multicolumn{6}{|c|}{ ANT } \\
\hline & & NP & FS & BR & KS & LS & ES & $\mathrm{BF}$ & CA & & WW & WS & IO & WP & RS & BA \\
\hline \multirow{7}{*}{$19 \mathrm{~V}$} & JAN & 0.45 & 0.51 & 0.52 & 0.46 & 0.37 & 0.35 & 0.38 & 0.37 & JUL & 0.45 & 0.46 & 0.37 & 0.45 & 0.52 & 0.48 \\
\hline & FEB & 0.36 & 0.47 & 0.51 & 0.50 & 0.44 & 0.36 & 0.39 & 0.33 & AUG & 0.53 & 0.45 & 0.34 & 0.43 & 0.94 & 0.59 \\
\hline & MAR & 0.39 & 0.41 & 0.49 & 0.45 & 0.30 & 0.29 & 0.36 & 0.36 & SEP & 0.56 & 0.46 & 0.40 & 0.49 & 0.91 & 0.72 \\
\hline & APR & 0.38 & 0.49 & 0.49 & 0.38 & 0.31 & 0.27 & 0.33 & 0.33 & OCT & 0.91 & 0.67 & 0.55 & 0.47 & 1.01 & 1.00 \\
\hline & MAY & 0.24 & 0.73 & 0.40 & 0.33 & 0.28 & 0.68 & 0.56 & 0.18 & NOV & 2.73 & 0.79 & 2.59 & 0.60 & 1.22 & 1.45 \\
\hline & JUN & 1.83 & 2.50 & 1.76 & 1.68 & 2.80 & 6.50 & 5.64 & 1.56 & DEC & 3.42 & 1.74 & 1.60 & 1.18 & 1.81 & 3.29 \\
\hline & & NP & FS & BR & $\mathrm{KS}$ & LS & ES & $\mathrm{BF}$ & $\mathrm{CA}$ & & WW & WS & IO & WP & $\mathrm{RS}$ & BA \\
\hline \multirow{8}{*}{$19 \mathrm{H}$} & JAN & 0.25 & 0.40 & 0.25 & 0.23 & 0.22 & 0.22 & 0.24 & 0.22 & JUL & 0.54 & 0.46 & 0.18 & 0.79 & 0.81 & 1.35 \\
\hline & FEB & 0.22 & 0.34 & 0.26 & 0.20 & 0.23 & 0.21 & 0.23 & 0.20 & AUG & 0.58 & 0.26 & 0.15 & 0.84 & 1.60 & 1.12 \\
\hline & MAR & 0.40 & 0.36 & 0.41 & 0.32 & 0.32 & 0.33 & 0.37 & 0.42 & SEP & 0.97 & 0.35 & 0.32 & 0.74 & 1.12 & 1.42 \\
\hline & APR & 0.23 & 0.55 & 0.32 & 0.29 & 0.17 & 0.14 & 0.39 & 0.23 & OCT & 1.83 & 1.23 & 0.77 & 0.73 & 1.20 & 1.48 \\
\hline & MAY & 0.31 & 1.82 & 0.99 & 0.64 & 0.57 & 1.74 & 1.59 & 0.39 & NOV & 3.36 & 1.84 & 3.37 & 1.32 & 2.01 & 2.32 \\
\hline & JUN & 4.81 & 6.16 & 4.99 & 4.81 & 6.67 & 10.50 & 9.71 & 4.61 & DEC & 7.33 & 4.36 & 2.70 & 3.23 & 4.27 & 6.48 \\
\hline & & \multicolumn{8}{|c|}{ ARC } & & \multicolumn{6}{|c|}{ ANT } \\
\hline & & NP & FS & BR & $\mathrm{KS}$ & LS & ES & $\mathrm{BF}$ & $\mathrm{CA}$ & & WW & WS & IO & WP & $\mathrm{RS}$ & BA \\
\hline \multirow{7}{*}{$37 \mathrm{~V}$} & JAN & 1.00 & 1.17 & 1.21 & 0.98 & 0.86 & 0.82 & 0.84 & 0.88 & JUL & 1.05 & 1.06 & 0.81 & 1.13 & 1.28 & 1.34 \\
\hline & FEB & 0.82 & 1.11 & 1.23 & 1.17 & 0.94 & 0.86 & 0.86 & 0.78 & AUG & 1.59 & 1.26 & 1.01 & 1.56 & 2.21 & 1.98 \\
\hline & MAR & 0.84 & 0.93 & 1.12 & 0.97 & 0.69 & 0.64 & 0.77 & 0.76 & SEP & 1.88 & 1.33 & 1.17 & 1.71 & 2.88 & 2.64 \\
\hline & APR & 0.74 & 1.34 & 1.18 & 0.81 & 0.70 & 0.61 & 0.79 & 0.60 & OCT & 3.56 & 2.28 & 1.35 & 1.72 & 3.38 & 3.56 \\
\hline & MAY & 0.72 & 2.48 & 1.46 & 1.06 & 1.02 & 2.43 & 2.14 & 0.67 & NOV & 4.26 & 3.07 & 2.41 & 2.16 & 4.20 & 4.33 \\
\hline & JUN & 6.07 & 6.22 & 5.98 & 5.61 & 6.07 & 6.35 & 6.29 & 6.07 & DEC & 5.67 & 4.77 & 3.06 & 3.45 & 5.09 & 4.51 \\
\hline & & NP & FS & $\mathrm{BR}$ & $\mathrm{KS}$ & LS & ES & $\mathrm{BF}$ & $\mathrm{CA}$ & & WW & WS & IO & WP & $\mathrm{RS}$ & BA \\
\hline \multirow{8}{*}{$37 \mathrm{H}$} & JAN & 0.82 & 0.96 & 0.98 & 0.82 & 0.70 & 0.66 & 0.69 & 0.71 & JUL & 0.98 & 0.92 & 0.66 & 1.14 & 1.22 & 1.70 \\
\hline & FEB & 0.66 & 0.91 & 0.97 & 0.95 & 0.76 & 0.69 & 0.71 & 0.63 & AUG & 1.11 & 0.94 & 0.79 & 1.32 & 2.10 & 1.58 \\
\hline & MAR & 0.79 & 0.76 & 0.99 & 0.86 & 0.63 & 0.61 & 0.72 & 0.73 & SEP & 1.49 & 0.97 & 0.94 & 1.33 & 1.99 & 2.06 \\
\hline & APR & 0.66 & 1.18 & 0.99 & 0.73 & 0.62 & 0.54 & 0.81 & 0.55 & OCT & 2.91 & 2.10 & 1.19 & 1.38 & 2.34 & 2.49 \\
\hline & MAY & 0.68 & 2.85 & 1.65 & 1.16 & 1.01 & 2.88 & 2.61 & 0.76 & NOV & 3.78 & 2.84 & 2.62 & 1.99 & 3.38 & 3.18 \\
\hline & JUN & 6.83 & 6.77 & 6.73 & 6.91 & 7.33 & 8.87 & 8.42 & 6.82 & DEC & 6.1 & 4.95 & 2.93 & 3.89 & 4.87 & 5.20 \\
\hline & & \multicolumn{8}{|c|}{$\mathrm{ARC}$} & & \multicolumn{6}{|c|}{ ANT } \\
\hline & & NP & FS & $\mathrm{BR}$ & $\mathrm{KS}$ & LS & ES & $\mathrm{BF}$ & $\mathrm{CA}$ & & WW & WS & IO & WP & $\mathrm{RS}$ & BA \\
\hline \multirow{7}{*}{$85 \mathrm{~V}$} & JAN & 2.59 & 3.22 & 3.23 & 2.64 & 2.17 & 2.03 & 2.11 & 2.14 & JUL & 2.89 & 2.88 & 2.33 & 3.19 & 3.49 & 3.62 \\
\hline & FEB & 1.87 & 2.81 & 2.76 & 2.70 & 2.10 & 1.95 & 2.03 & 1.75 & AUG & 3.83 & 3.01 & 2.50 & 3.82 & 5.22 & 5.09 \\
\hline & MAR & 2.07 & 2.58 & 2.60 & 2.33 & 1.81 & 1.68 & 1.83 & 1.74 & SEP & 4.40 & 2.95 & 2.63 & 3.89 & 6.05 & 6.53 \\
\hline & APR & 1.86 & 3.80 & 2.79 & 1.99 & 1.83 & 1.69 & 1.99 & 1.69 & OCT & 7.06 & 4.59 & 2.61 & 3.69 & 6.91 & 8.00 \\
\hline & MAY & 1.62 & 5.27 & 3.04 & 2.28 & 2.36 & 4.80 & 4.47 & 1.70 & NOV & 8.20 & 6.23 & 4.67 & 4.38 & 8.45 & 9.73 \\
\hline & JUN & 12.34 & 12.33 & 12.65 & 12.76 & 12.23 & 11.67 & 11.77 & 12.10 & DEC & 11.82 & 9.61 & 6.46 & 7.51 & 9.91 & 11.21 \\
\hline & & NP & FS & BR & $\mathrm{KS}$ & LS & ES & $\mathrm{BF}$ & $\mathrm{CA}$ & & WW & WS & IO & WP & $\mathrm{RS}$ & BA \\
\hline \multirow{6}{*}{$85 \mathrm{H}$} & JAN & 2.44 & 2.98 & 3.04 & 2.49 & 2.04 & 1.91 & 1.99 & 2.01 & JUL & 2.70 & 2.66 & 2.19 & 3.03 & 3.17 & 3.60 \\
\hline & FEB & 1.76 & 2.60 & 2.59 & 2.56 & 1.98 & 1.84 & 1.92 & 1.66 & AUG & 3.36 & 2.77 & 2.35 & 3.47 & 4.84 & 4.35 \\
\hline & MAR & 1.96 & 2.35 & 2.45 & 2.21 & 1.71 & 1.59 & 1.73 & 1.65 & SEP & 3.87 & 2.69 & 2.44 & 3.43 & 4.98 & 5.46 \\
\hline & APR & 1.77 & 3.42 & 2.60 & 1.88 & 1.74 & 1.60 & 1.87 & 1.60 & OCT & 6.15 & 4.29 & 2.39 & 3.21 & 5.61 & 6.48 \\
\hline & MAY & 1.50 & 5.03 & 2.84 & 2.22 & 2.14 & 4.62 & 4.27 & 1.61 & NOV & 7.20 & 5.53 & 4.49 & 3.85 & 7.03 & 7.59 \\
\hline & JUN & 11.10 & 10.71 & 11.23 & 11.45 & 10.85 & 10.50 & 10.48 & 10.86 & DEC & 9.03 & 8.33 & 5.63 & 6.62 & 8.11 & 8.17 \\
\hline
\end{tabular}

in both hemispheres. Two key properties are penetration depth and snow density. Their temporal changes are shown in Fig. 7. We calculated the penetration depth by accumulating layer transmissivities and determining the depth at which a fraction of $1 / e$ of the signal contributes to the emitted signal at the surface. Maximum values were constrained to the maximum snow depth of $30 \mathrm{~cm}$ (snow penetration depth). Figure $7 \mathrm{a}$ shows that the mean monthly microwave snow penetration depth decreases from winter to summer. In month 6 , it is lower in the Arctic than in the Antarctic $(12.5 \mathrm{~cm}$ vs. $20 \mathrm{~cm})$. At $37 \mathrm{GHz}$ the penetration depth in the Arctic starts to deviate from the Antarctic already during month 5
(May/November) with a value of $17 \mathrm{~cm}$ (Antarctic: $19 \mathrm{~cm}$ ) and $10 \mathrm{~cm}$ (Antarctic: $17 \mathrm{~cm}$ ) in month 6 (June/December). The rate at which the penetration depth decreases throughout the season is smaller for $19 \mathrm{GHz}$ than for $37 \mathrm{GHz}$. This is due to the stronger sensitivity of $\mathrm{Tb}$ values at $37 \mathrm{GHz}$ than at $19 \mathrm{GHz}$ to atmospheric variability and associated changes in the vertical snow profile. In the pre-melt period, the bulk snow density increases on average faster in the Antarctic (Fig. 7b). This is rapidly reversed when the advanced melt starts in the Arctic in June and wet snow with high densities is prevalent. Monthly hemispheric average $37 \mathrm{~V}$ emissivities are higher in the Antarctic (Fig. 7c) and less sensitive 
a)

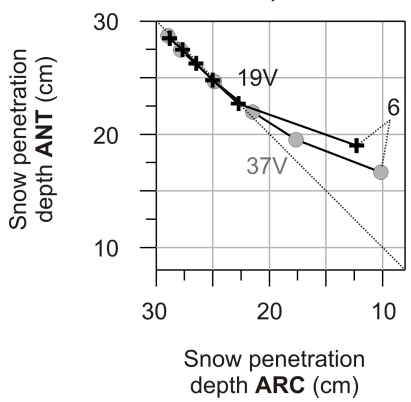

b)

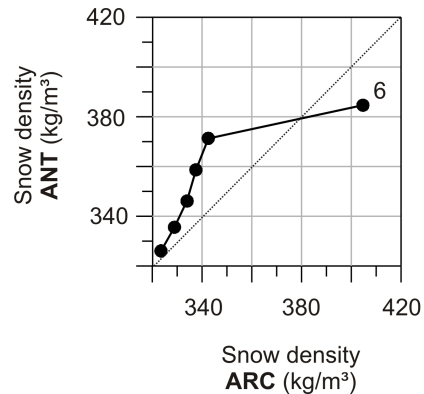

c)

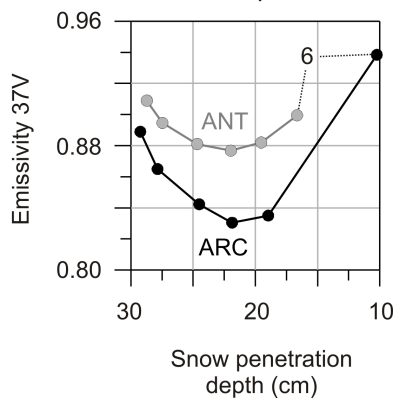

Fig. 7. (a) Monthly average snow penetration depth, Arctic vs. Antarctic for $19 \mathrm{~V}$ (black) and 37V (grey), (b) Monthly average snow density, Arctic vs. Antarctic, (c) Monthly average $37 \mathrm{~V}$ emissivity in relation to snow penetration depth. Each point for the months of January to June (Arctic) and July to December (Antarctic; last months are highlighted by number "6" to indicate the direction of the seasonal evolution), averaged for all regions, 2000-2009.

to a decrease in penetration depth before the melt season starts. This reveals that the processes that cause the penetration depth to cease throughout the season have a larger impact on the mean $37 \mathrm{~V}$ emissivity in the Arctic than in the Antarctic. As shown above, however, this does not hold for the emissivity variability, which is larger in the Antarctic.

\subsection{Multi-year emissivity trends}

Multi-year emissivity trends from 2000 to 2009 were derived for both hemispheres and for all regions separately. Although we recognize that the 10-year period is rather short for a trend analysis, we chose to present these trends as shifts in seasonal transitions have been reported by e.g. Markus et al. (2009). Our data revealed that significant trends (level of significance $\alpha=0.05$ ) of increasing emissivity are found almost exclusively in the Weddell Sea (WS) region for all channels (except 19H) in the months of November and December. Although being small $(0.01,0.04$ and 0.08 per decade in the month of December for $19 \mathrm{~V}, 37 \mathrm{~V}$ and $85 \mathrm{~V}$, respectively) the 10-year time series gives an indication of a tendency towards larger emissivities that might be associated with increased melt rates or earlier melt onset. Apart from the Weddell Sea, small but significant trends are found only for the Fram Strait region in February (19V: 0.005/decade, 37V: 0.007/decade) and for the Beaufort Sea in June (85H: 0.04/decade). Although the time series is rather short, the positive emissivity trend in the Weddell Sea is mostly caused by an increasing impact of melt events during the months of November and December. This means that an emissivity increase will saturate when melt events become characteristic of the advanced melt stage (Livingstone et al., 1997) and not continue at the same rate.

\section{Discussion}

In contrast to e.g. Montpetit et al. (2013), Brucker et al. (2011), this study does not intend to realistically simulate measured $\mathrm{Tb}$ values and their changes because there are too many ambiguities arising from the comparison of point-scale and satellite data mentioned above. Instead of accurately simulating real snow packs and associated $\mathrm{Tb}$ data, we focus on studying the impact of atmospheric forcing on emissivity variations for an idealized snow pack and determine its regional and hemispheric characteristics. We believe that this approach and the obtained emissivity variations reveal what we call the "background emissivity variability" due to atmospheric forcing which we propose is the minimum natural emissivity variation that has to be considered when evaluating ice concentration retrievals for regions with high-sea concentrations in a seasonal and regional context. As such, our study extends the conclusion of Andersen et. al (2007) who showed that, especially at high sea-ice concentrations, ice concentration accuracy suffers from emissivity variations in the snowpack.

It is well known that the inherent noise of sea-ice concentration retrievals is on average as high as $\pm 5 \%$ (Meier and Notz, 2010; Meier, 2005). With the results presented here, we provide some context for these variations in high iceconcentration regions and show regional and seasonal differences. Sources of ambiguity for sea-ice concentration and snow depth retrieval are manifold and variations in emissivity represent just one problem next to spatial inhomogeneity of surfaces, the presence of thin ice (Kwok et al., 1997) and atmospheric disturbances (e.g. Cavalieri et al., 1995; Markus and Dokken, 2002; Spreen et al., 2008). We consider the presented emissivity variability representative for the atmospherically induced variability found over highconcentration sea ice. Even if an algorithm would implement monthly tie points to account for seasonal variations and weather effects, this tie point would be subject to the regional, diurnal and inter-annual emissivity variations inherent to a specific region.

We speculate that atmospheric water vapour, cloud liquid water and rain could probably smooth the emissivity variability we present here. Nevertheless, we consider our results as 
a seasonal background variability that needs to be taken into account even when weather filters are applied since these filters are implemented to reduce the impact of the atmosphere on upwelling brightness temperatures, not to reduce the impact of atmospheric-induced surface emissivity variations due to atmospheric forcing (Gloersen and Cavalieri, 1986).

An assessment of the contribution of different sources for varying brightness temperatures over high-concentration sea ice goes beyond the scope of this paper. The simplification that snow fall is not considered might cause an underestimation of snow compaction which could result in a bias of mean brightness temperatures. The monthly emissivity variations due to seasonal changes will however be less affected by the missing accumulation, which is indicated by the low sensitivity of emissivity variability in SNTHERM initialization. We did not include the effect of flooding and snow ice formation and hence, the contribution of salty slush and gap layers (Ackley et al., 2008) that probably play an important role for microwave brightness temperatures found over Antarctic sea ice as well (Massom et al., 2001; Haas et al., 2001; Nicolaus et al., 2009). A completely new thermodynamic snow/ice model would be required to simulate these processes and thereby enable an assessment of combined snow and ice ambiguities and their regional characteristics.

A monthly and regionally determined microwave emissivity variability as presented in this study can help in determining optimized tie points for the definition of transfer functions from satellite measurements of the surface brightness temperature over high-concentration sea ice to surface properties. In addition, the potential for an improved snow depth retrieval can be investigated from the combined snow and microwave data.

\section{Conclusions}

The thermodynamic snow model SNTHERM and the microwave emission model for layered snowpacks (MEMLS) were used to identify the contribution of regional patterns in atmospheric energy fluxes to surface emissivity variations on Arctic and Antarctic sea ice between 2000 and 2009.

The microwave emissivities at 19,37 and $85 \mathrm{GHz}$ are characterized by pronounced seasonal variability. The combined regional, diurnal and inter-annual emissivity variability increases from winter to early summer and Antarctic regions are affected by a larger range of emissivity values with a tendency towards higher mean emissivities than in the Arctic. In the pre-melt period, the variations in surface microwave emissivity due to diurnal, regional and inter-annual variability of atmospheric forcing reach up to $0.034,0.043$, and 0.097 for $19 \mathrm{GHz}, 37 \mathrm{GHz}$ and $85 \mathrm{GHz}$ channels, respectively (Table 2). Given an emissivity contrast of sea ice and calm open water which amounts to approximately $0.4,0.3$ and 0.1 for $19 \mathrm{~V}, 37 \mathrm{~V}$, and $85 \mathrm{~V}$, respectively (Eppler et al., 1992) these computed emissivity variabilities would imply significant complications for the discrimination between sea ice and open water in the late spring/early summer season especially at $85 \mathrm{GHz}$ and similar frequencies.

Over the simulation period significant positive emissivity trends are found in the Weddell Sea region for all channels (except 19H) in November and December, which might be associated with increased melt rates or earlier melt onset.

The obtained emissivity data characterize the background emissivity variability of snow-covered first-year sea ice due to atmospheric forcing and contribute to a better understanding of sea-ice concentration and snow-depth product accuracies at high sea-ice concentrations. The results need to be interpreted in the context of assumptions and simplifications.

Acknowledgements. This work was supported by the Deutsche Forschungsgemeinschaft (DFG) in the framework of the priority programme "Antarctic research with comparative investigations in Arctic ice areas" by a grant to WI 33114/-1 and WI 3314/-2. We are very grateful to Rasmus T. Tonboe from the Danish Meteorological Institute who kindly provided his sea-ice version of MEMLS. Sea-ice brightness temperatures and sea-ice concentrations were provided by the US National Snow and Ice Data Center (NSIDC). The European Center for Medium Range Weather Forecast (ECMWF) offered ERA interim data free of charge. Leif Toudal Pedersen, Rasmus Tonboe and Günther Heinemann provided very valuable comments on this research. We also acknowledge the very detailed and helpful reviews by three anonymous referees and Hajo Eicken.

Edited by: H. Eicken

\section{References}

Ackley, S. F., Lewis, M. J., Fritsen, C. H., and Hongjie, X.: Internal melting in Antarctic sea ice: Development of "gap layers", Geophys. Res. Lett., 35, L11502, doi:10.1029/2008GL033644, 2008.

Andersen, S., Tonboe, R., Kaleschke, L., Heygster, G., and Pedersen, L. T.: Intercomparison of passive micorwave sea ice concentration retrievals over the high-concentration Arctic sea ice, J. Geophys. Res., 112, C08004, doi:10.1029/2006JC003543, 2007.

Andreas, E. L., and Ackley, S. F.: On the differences in ablation seasons of Arctic and Antarctic sea ice, J. Atmos. Sci., 389, 440 447, 1982

Andreas, E. L., Jordan, R. E., and Makshtas, A. P.: Simulations of Snow, Ice and Near-Surface Atmospheric Processes on Ice Station Weddell, J. Hydrometeorol., 5, 611-624, 2004.

Belchansky, G., Douglas, D. C., Mordvintsev, I., and Platonov, N.: Estimating the time of melt onset and freeze onset over Arctic sea ice area using active and passive microwave data, Remote Sens. Environ., 92, 21-39, 2004.

Brucker, L., Royer, A., Picard, G., Langlois, A., and Fily, M.: Hourly simulations of seasonal snow microwave brightness temperature using coupled snow evolution-emission models in Quebec, Canada, Remote Sens. Environ., 115, 1966-1977, 2011. 
Cavalieri, D. J.: A microwave technique for mapping thin ice, J. Geophys. Res., 99, 12561-12572, 1994.

Cavalieri, D. J., Gloersen, P., and Campbell, W. J.: Determination of sea-ice parameters with the NIMBUS 7 scanning multichannel microwave radiometer, J. Geophys. Res., 89, 5355-5369, 1984.

Cavalieri, D. J., Burns, B. A., and Onstott, R. G.: Investigation of the Effects of Summer Melt on the Calculation of Sea Ice Concentration Using Active and Passive Microwave Data, J. Geophys. Res., 95, 5359-5369, 1990.

Cavalieri, D. J., St. Germain, K. M., and Swift, C. T.: Reduction of weather effects in the calculation of sea-ice concentration with the DMSP SSM/I, J. Glaciol., 41, 455-464, 1995.

Cavalieri, D. J., Parkinson, C. L., Gloersen, P., and Zwally, H. J.: Sea Ice Concentrations from Nimbus-7 SMMR and DMSP SSM/ISSMIS Passive Microwave Data, [2002-2009]. Boulder, Colorado USA: National Snow and Ice Data Center, Digital media, updated yearly, 1996.

Cavalieri, D. J., and Parkinson, C. L.: Antarctic sea ice variability and trends, 1979-2006, J. Geophy. Res., 113, C07004, doi:10.1029/2007JC004558, 2008.

Cavalieri, D. J., Parkinson, C. L., Gloersen, P., and Zwally, H. J.: Arctic and Antarctic Sea Ice Concentrations from Multichannel Passive-microwave Satellite Data Sets: October 1978 to December 1996, User's Guide, NASA Technical Memorandum 104647, 17 pp., 1997.

Comiso J. C.: Characteristics of Arctic Winter Sea Ice From Satellite Multispectral Microwave Observations, J. Geophys. Res., 91, 975-994, 1986

Comiso, J. C. and Kwok, R.: Surface and radiative characteristics of the summer Arctic sea ice cover from multisensory satellite observations, J. Geophys. Res., 101, 28397-28416, 1996.

Comiso, J. C., Cavalieri, D. J., Parkinson, C. L., and Gloersen, P.: Passive Microwave Algorithms for Sea Ice Concentration: A Comparison of Two Techniques, Rem. Sens. Environ., 60, 357384, 1997.

Dee, D. P., Uppala, S. M., Simmons, A. J., Berrisford, P., and 32 others: The ERA-Interim reanalysis: configuration and performance of the data assimilation system. Q. J. Roy. Meteorol. Soc., 137, 553-597, doi:10.1002/qj.828, 2011.

Drobot, S. D. and Anderson, M. R.: An improved method for determining snowmelt onset dates over Arctic sea ice using SMMR and SSM/I data, J. Geophys. Res., 106, 24033-24049, 2001.

Durand, M., Kim, E., and Margulis, S.: Quantifying uncertainty in modeling snow microwave radiance for a mountain snowpack at the point-scale, including stratigraphic effects, IEEE T. Geosci. Remote, 46, 1753-1767, 2008.

Eisenman, I., Meier, W. N., and Norris, J. R.: A spurious jump in the satellite record: is Antarctic sea ice really expanding?, The Cryosphere Discuss., 8, 273-288, doi:10.5194/tcd-8-273-2014, 2014.

Eppler, D., Farmer, L., Lohanick, A., Anderson, M., Cavalieri, D., Comiso, J., Gloersen, P., Garrity, C., Grenfell, T., Hallikainen, M., Maslanik, J., Mätzler, C., Melloh, R., Rubinstein, I., and Swift, C.: Passive microwave signatures of sea ice, in: Microwave Remote Sensing of Sea Ice, edited by: Carsey, F. D., no. 68 in Geophys. Monogr., American Geophysical Union, 1992.

Garrity, C.: Characterization of Snow on Floating Ice and Case Studies of Brightness Temperature Changes Durig the Onset of Melt, in: Microwave Remote Sensing of Sea Ice, edited by:
Carsey, F. D., no. 68 in Geophysical Monograph, American Geophysical Union, 1992.

Gloersen, P. and Cavalieri, D. J.: Reduction of Weather Effects in the Calculation of Sea Ice Concentration from Microwave Radiances, J. Geophys. Res., 91, 3913-3919, 1986.

Haas, C.: The seasonal cycle of ERS scatterometer signatures over perennial Antarctic sea ice and associated surface ice properties and processes, Ann. Glaciol., 33, 69-73, 2001.

Jordan, R. E.: A one-dimensional temperature model for a snow cover, Special Report 91-16, U.S. Army Corps of Eng. Cold Regions Research and Engineering Laboratory, Hanover, N. H., 1991.

Jordan, R. E., Andreas, E. L., and Makshtas, A. P.: Heat budget of snow-covered sea ice at North Pole 4, J. Geophys. Res., 104 7785-7806, 1999.

Kwok, R., Comiso, J. C., Martin, S., and Drucker, R.: Ross Sea polynyas: Response of ice concentration retrievals to large areas of thin ice, J. Geophys. Res., 112, C12012, doi:10.1029/2006JC003967, 2007.

Langlois, A., Royer, A., Derksen, C., Montpetit, B., Dupoint, F., and Gota, K.: Coupling the snow thermodynamic model SNOWPACK with the microwave emission model of layered snowpacks for subarctic and arctic snow water equivalent retrievals, Water Resour. Res., 48, W12524, doi:10.1029/2012WR012133, 2012.

Livingstone, C. E., Onstott, R. G., Arsenault, L. D., Gray, A. L., and Singh, K. P.: Microwave sea-ice signatures near the onset of melt, IEEE T. Geosci. Remote Sens., 25, 174-187, 1997.

Lubin, D., Garrity, C., Ramseier, R. O., and Whritner, R. H.: Total Sea Ice Concentration Retrieval from the SSM/I 85.5 GHz Channels during the Arctic Summer, Rem. Sens. Environ., 62, 63-76, 1997.

Mätzler, C.: Relation between grain-size and correlation length of snow, J. Glaciol., 48, 461-466, 2002.

Mätzler, C. and Wiesmann, A.: Extension of the Microwave Emission Model of Layered Snowpacks to Coarse-Grained Snow, Remote Sens. Environ., 70, 317-325, 1999

Markus, T. and Cavalieri, D. J.: Snow Depth Distribution over Sea Ice in the Southern Ocean from Satellite Passive Microwave Data. Antarctic Sea Ice: Physical Processes, Interactions, and Variability, Antarctic Research Series 74, 19-39. Washington, DC, USA, American Geophysical Union, 1998.

Markus, T. and Cavalieri, D. J.: An enhancement of the NASA Team sea ice algorithm, IEEE T. Geosci. Remote Sens., 38, 13871398, 2000.

Markus, T. and Dokken, S.: Evaluation of Late Summer Passive Microwave Arctic Sea Ice Retrievals, IEEE T. Geosci. Remote Sens., 40, 348-356, 2002.

Markus, T., Powell, D. C., and Wang, J. R.: Sensitivity of passive microwave snow depth retrievals to weather effects and snow evolution. IEEE T. Geosci. Rem. Sens., 44(1), 68-77, 2006

Markus, T., Stroeve, J. C., and Miller, J.: Recent changes in Arctic sea ice melt onset, freezeup, and melt season length, J. Geophys. Res., 114, C12024, doi:10.1029/2009JC005436, 2009.

Maslanik, J. and Stroeve, J. C.: DMSP SSM/I-SSMIS Daily Polar Gridded Brightness Temperatures. Version 4, 2000-2009. Boulder, Colorado USA: NASA DAAC at the National Snow and Ice Data Center, 2004, updated 2012.

Massom, R. A., Eicken, H., Haas, C., Jeffris, M. O., Drinkwater, M. R., Sturm, M., Worby, A. P., Wu, X., Lytle, V. I., Ushio, S., 
Morris, K., Reid, P. A., Warren, S. G., and Allison, I.: Snow on Antarctic ice, Rev. Geophys., 39, 413-445, 2001.

Meier, W. N.: Comparison of passive microwave ice concentration algorithm retrievals with AVHRR imagery in Arctic peripheral seas, IEEE T. Geosci. Rem. Sens., 43, 1324-1337, 2005.

Meier, W. and Notz, D.: A note on the accuracy and reliability of satellite-derived passive microwave estimates of sea-ice extent, Climate and Cryosphere Sea Ice Working Group Consensus Document, World Climate Research Program, http://www.arcus.org/files/page/documents/1707/GCW_CliC_ Sea_ice_Reliability.pdf, 2010.

Montpetit, B., Royer, A., Roy, A., Langlois, A., and Derksen, C.: Snow Microwave Emission Modeling of Ice Lenses Within a Snowpack Using the Microwave Emission Model for Layered Snowpacks, IEEE T. Geosci. Remote, 51, 4705-4717, 2013.

Nicolaus, M., Haas, C., Bareiss, J., and Willmes, S.: A model study of differences of snow thinning on Arctic and Antarctic first-year sea ice during spring and summery, Ann. Glaciol., 44, 147-153, 2006.

Nicolaus, M., Haas, C., and Willmes, S.: Evolution of first-year and second-year snow properties on sea ice in the Weddell Sea during spring-summer transition, J. Geophys. Res., 114, D17109, doi:10.1029/2008JD011227, 2009.

Parkinson, C. L. and Cavalieri, D. J.: Arctic sea ice variability and trends, 1979-2006, J. Geophy. Res., 113, C07003, doi:10.1029/2007JC004558, 2008.

Powell, D. C., Markus, T., Cavalieri, D. J., Gasiewski, A. J., Klein, M., Maslanik, J., Stroeve, J. C., and Sturm, M.: Microwave Signatures of snow on sea ice: Modeling. IEEE T. Geosci. Remote Sens., 44, 3091-3102, 2006

Spreen, G., Kaleschke, L., and Heygster, G.: Sea ice remote sensing using AMSR-E $89 \mathrm{GHz}$ channels, J. Geophys. Res., 113, C02S03, doi:10.1029/2005JC003384, 2008.
Stroeve, J. C., Serreze, M. C., Holland, M. M., Kay, J. E., Maslanik, J., and Barrett, A.P.: The Arctic's rapidly shrinking sea ice cover: A research synthesis. Clim. Change, doi:10.1007/s10584-0110101-1, 2012.

Svendsen, E., Mätzler, C., and Grenfell, T. C.: A model for retrieving total sea ice concentration from a spaceborne dual-polarized passive microwave instrument operating near $90 \mathrm{GHz}$, Int. J. Remote Sens., 8, 1479-1487, 1987.

Tonboe, R. T.: The simulated sea ice thermal microwave emission at window and sounding frequencies, Tellus A, 62, 333-344, 2010.

Tonboe, R. T., Heygster, G., Pedersen, L. T., and Andersen, S.: Sea ice emission modelling, in: Thermal Microwave Radiation: Applications for Remote Sensing, edited by: Mätzler, C., IET Electromagnetic Wave Series 52, London, UK, 382-400, 2006.

Warren, S. G., Rigor, I. G., Untersteiner, N., Radionov, V. F., Bryazgin, N. N., Aleksandrov, V., and Colony, R.: Snow depth on Arctic sea ice, J. Climate, 12, 1814-1829, 1999.

Wiesmann, A. and Mätzler, C.: Microwave emission model of layered snowpacks. Rem. Sens. Env., 70, 307-316, 1999.

Wiesmann, A., Fierz, C., and Mätzler, C.: Simulation of microwave emission from physically modeled snowpacks, Ann. Glaciol., 31, 397-401, 2000.

Willmes, S., Bareiss, J., Haas, C., and Nicolaus, M.: The importance of diurnal processes for the seasonal cycle of sea-ice microwave brightness temperatures during eraly summer in the Weddell Sea, Antarctica, Ann. Glaciol., 44, 297-302, 2006.

Willmes, S., Haas, C., Bareiss, J., and Nicolaus, M.: Satellite microwave observations of the interannual variability of snowmelt on sea ice in the Southern Ocean, J. Geophys. Res., 114, C03006, doi:10.1029/2008JC004919, 2009. 